\title{
Short-term effective treatment of CNS metastasis of sarcomatoid renal cell carcinoma with temozolomide and pegylated liposomal doxorubicin: A case report Dagmar Beier*1, Gerhard Schuierer ${ }^{2}$, Christoph P Beier ${ }^{1}$ and Ulrich Bogdahn ${ }^{1}$
}

Address: ${ }^{1}$ Department of Neurology, Medical School, University of Regensburg and District Medical Center Regensburg, Universitätsstrasse 84 , 93053 Regensburg, Germany and 2Institute of Neuroradiology, District Medical Center Regensburg, Universitätsstrasse 84, 93053 Regensburg, Germany

Email: Dagmar Beier* - dagmar.beier@medbo.de; Gerhard Schuierer - gerhard.schuierer@medbo.de; Christoph P Beier - christoph.beier@gmx.de; Ulrich Bogdahn - ulrich.bogdahn@medbo.de

* Corresponding author

Published: 3 October 2008

Cases Journal 2008, 1:210 doi:10.1186/1757-1626-1-210

This article is available from: http://www.casesjournal.com/content/I/I/210

(c) 2008 Beier et al; licensee BioMed Central Ltd.

This is an Open Access article distributed under the terms of the Creative Commons Attribution License (http://creativecommons.org/licenses/by/2.0), which permits unrestricted use, distribution, and reproduction in any medium, provided the original work is properly cited.
Received: 17 September 2008

Accepted: 3 October 2008

\begin{abstract}
Sarcomatoid renal cell carcinoma represents high-grade transformation of different subtypes of renal cell carcinoma and is associated with a dismal prognosis and high resistance to chemotherapy. We report on the course of disease of a 63 years old patient undergoing a nearly complete remission of multiple intracranial and spinal metastatic lesions of a sarcomatoid renal cell carcinoma by a combined chemotherapy with temozolomide and pegylated liposomal doxorubicin.
\end{abstract}

\section{Case presentation}

In December 2004, a 63-year-old female, Caucasian patient presented in our hospital with progressive paraplegia due to multiple CNS metastasis of renal cell carcinoma (RCC). Already in January 2003, she had noticed a slowly progressive numbness of her right forearm and belt-shaped pain of her chest due to metastatic disease at the level of T1/2 causing compression of the spinal cord. Both, the RCC and the metastatic lesion were completely removed in February 2003. Pathological analysis of the renal cell tumor revealed a clear cell RCC, the intraspinal metastasis was characterized by mesenchymal appearance with epithelial components and areas with spindle cells. Based on the histological findings, the National Reference Center of Neuropathology made the diagnosis of an undifferentiated sarcoma - most likely a sarcomatoid metastasis of the clear cell RCC.
Spinal surgery was followed by local radiotherapy (cervical and upper thoracic spine, $50 \mathrm{~Gy}$; primary tumor site: $59.4 \mathrm{~Gy}$ ) and chemotherapy with temozolomide (three cycles, $1600 \mathrm{mg}$ per cycle). After one year, MRI revealed multiple asymptomatic relapses affecting the clivus, C6, and T11-S1. Another local radiotherapy (Clivus-C6 and T11-S2, 50 Gy) was administered until July 2004. In July 2004 , the patient noted for the first time progressive prickling dysesthesias due to a new recurrence affecting T5-10. The patient then started palliative chemotherapy with thalidomide (200 mg orally every day).

Until December 2004, the patient further deteriorated and was finally unable to stand when presenting in our hospital. MRI showed a marked progression of all metastatic lesions in the CNS (Figure 1). We initiated chemotherapy with temozolomide orally $\left(200 \mathrm{mg} / \mathrm{m}^{2}\right)$ on five 

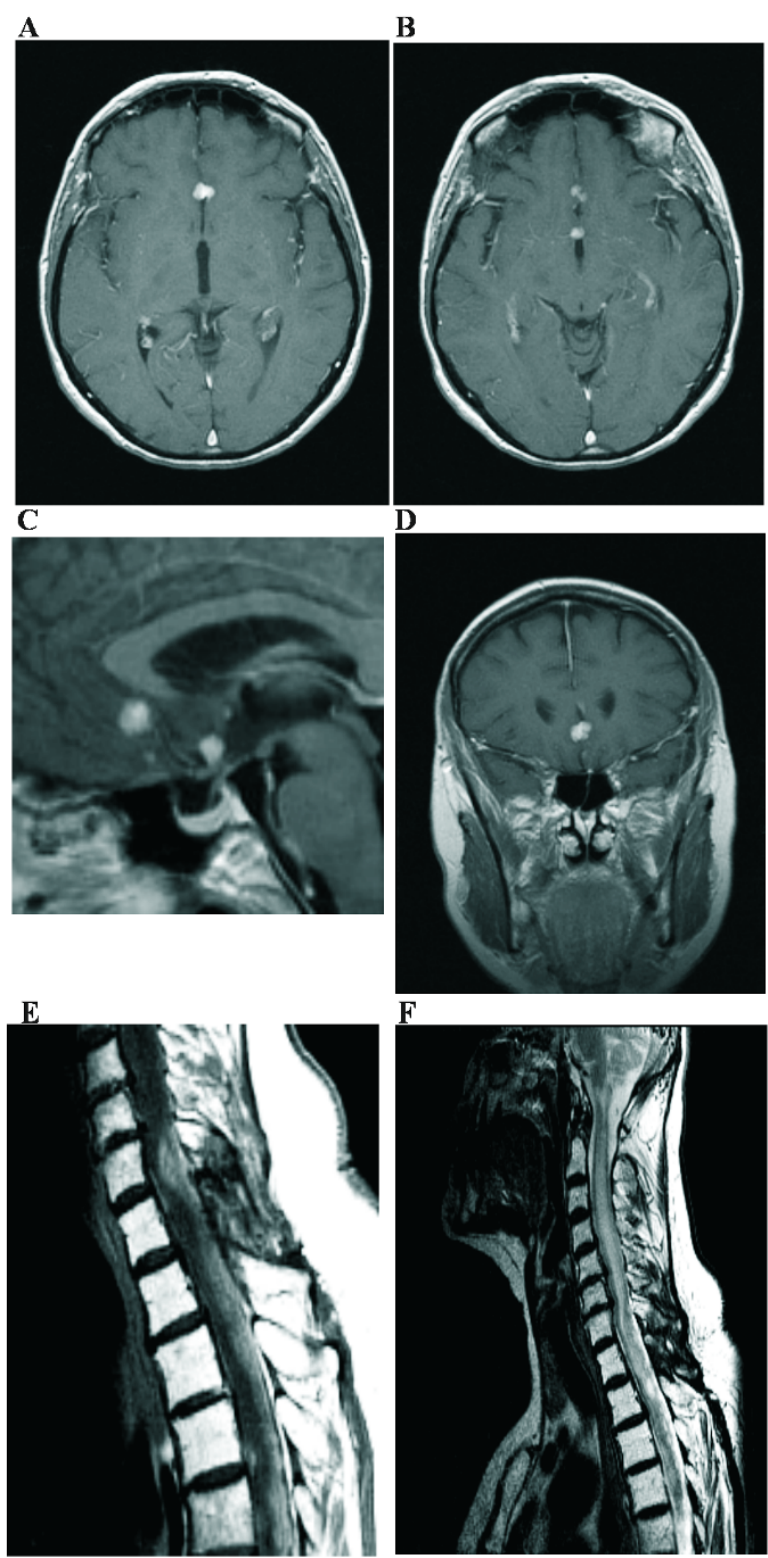

Figure I

December 2004: Contrast-enhanced axial (A, B), sagittal (C), and coronal (D) TI-weighted MR-images of the brain and sagittal TI- and T2-weighted MR-images (E, F) of the spine showing multiple intracranial metastatic nodules and extensive spinal involvement.

consecutive days every four weeks and pegylated liposomal doxorubicin intravenously $\left(20 \mathrm{mg} / \mathrm{m}^{2}\right.$ every two weeks). In addition, we treated the patient with methylprednisolone, glycerine, and thalidomide. The patient's clinical condition improved rapidly and four weeks later, she was able to climb four storeys with her walking frame. In January 2005, MRI showed a nearly complete remission of the intracranial metastases and a partial remission of the spinal lumps (Figure 2). The patient received the first cycle of chemotherapy regularly. Then, prolonged myelosuppression required dose reduction and finally the discontinuation of the chemotherapy before finishing the second cycle. In addition, the port for chemotherapy got infected and multiple septic abscesses occurred. After discontinuation of chemotherapy in March 2005 the symptoms reocurred due to regrowth of the metastases. As signs
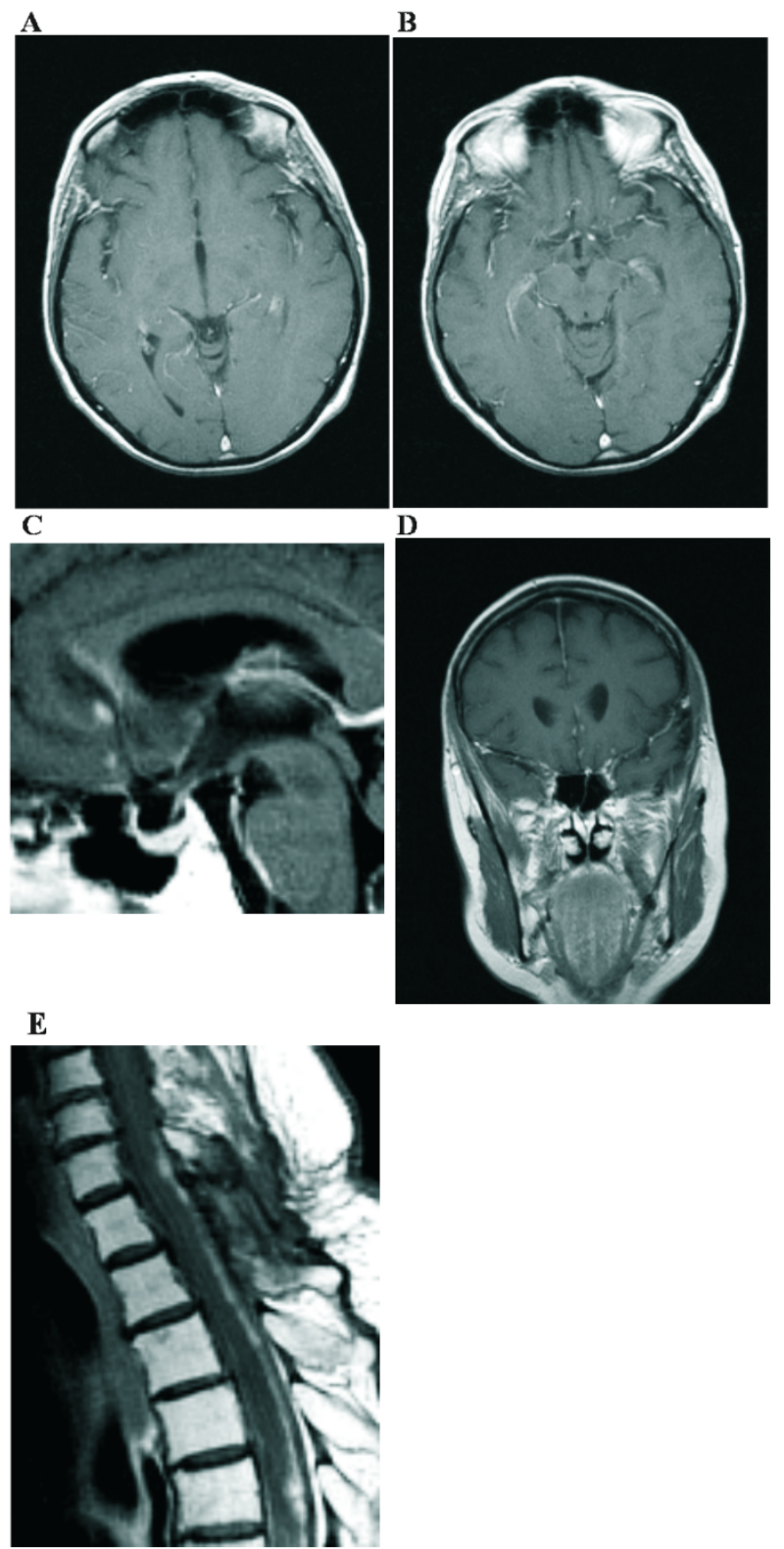

Figure 2

January 2005: Contrast-enhanced axial (A, B), sagittal (C), and coronal (D) TI-weighted MR-images of the brain and sagittal TI-weighted MR-image (E) of the spine demonstrating significant regression of the tumor. 
of inflammation still reoccurred intermittently, we were not able to restart chemotherapy. The patient was discharged and died in June 2005 due to progressive disease.

\section{Discussion}

Sarcomatoid RCC is not a distinct entity but represents a common histological phenotype after high-grade transformation of different subtypes of RCC [1]. It is associated with a dismal prognosis with tumors metastasizing earlier $[1,2]$. RCC are usually resistant to classical chemotherapeutic agents but there are several small case studies reporting on partial remissions of sarcomatoid RCC after doxorubicin-based chemotherapeutic protocols [3-7]. The rationale for combining temozolomide and pegylated liposomal doxorubicin was based on their anti-tumor activity, their good penetration of the blood-brain barrier, and no significant overlapping toxicities. The combined therapy usually is well tolerated $[8,9]$ and severe adverse events as seen in our patient are uncommon. To our knowledge, this is the first report on the effective treatment of multiple CNS metastasis of a sarcomatoid RCC with temozolomide and pegylated liposomal doxorubicin suggesting that the combination is treatment option for recurrent CNS metastasis of sarcomatoid RCC.

\section{Abbreviations}

RCC: renal cell carcinoma; CNS: Central nervous system; MRI: magnetic resonance imaging; $\mathrm{C} 1$ : cervical vertebra 1 ; T1: thoracic vertebra 1; S1: sacral vertebra 1 .

\section{Competing interests}

Christoph P. Beier has received reimbursements by Schering-Plough, Ulrich Bogdahn has received honoraria by Schering-Plough. Dagmar Beier and Gerhard Schuierer do not have competing interests.

\section{Authors' contributions}

$\mathrm{DB}$ and $\mathrm{UB}$ were the treating physicians of the patient $\mathrm{DB}$, $\mathrm{CPB}$, and $\mathrm{UB}$ interpreted the data and wrote the manuscript. GS provided the MRIs. All authors read and approved the manuscript.

\section{Consent}

Because the patient has deceased, written informed consent was obtained from the patient's husband for publication of this case report and accompanying images. A copy of the written consent is available for review by the Editorin-Chief of this journal.

\section{Acknowledgements}

We are in debt to Juergen Schlegel, $\mathrm{PhD}$ (Technische Universität München, Germany) for providing the histological results and to Thorsten Pietsch, $\mathrm{PhD}$ (University of Bonn, Germany) for valuable discussions.

\section{References}

I. Delahunt B: Sarcomatoid renal carcinoma: the final common dedifferentiation pathway of renal epithelial malignancies. Pathology 1999, 3 I : 185-190.

2. Cangiano T, Liao J, Naitoh J, Dorey F, Figlin R, Belldegrun A: Sarcomatoid renal cell carcinoma: biologic behavior, prognosis, and response to combined surgical resection and immunotherapy. J Clin Oncol 1999, I 7:523-528.

3. Sella A, Logothetis CJ, Ro JY, Swanson DA, Samuels ML: Sarcomatoid renal cell carcinoma. A treatable entity. Cancer I987, 60: $1313-1318$.

4. Bangalore N, Bhargava P, Hawkins MJ: Sustained response of sarcomatoid renal-cell carcinoma to MAID chemotherapy: case report and review of the literature. Ann Oncol 200 I, I 2:27I-274.

5. Rashid MH, Welsh CT, Bissada NK, Chaudhary UB: Complete response to adriamycin and ifosfamide in a patient with sarcomatoid renal cell carcinoma. Am J Clin Oncol 2005, 28: I07-I 08.

6. Lupera H, Theodore C, Ghosn M, Court BH, Wibault P, Droz JP: Phase II trial of combination chemotherapy with dacarbazine, cyclophosphamide, cisplatin, doxorubicin, and vindesine (DECAV) in advanced renal cell cancer. Urology 1989, 34:28I-283.

7. Shimomura T, Ikemoto I, Yamada H, Hayashi N, Ito H, Oishi Y: Sarcomatoid renal cell carcinoma with a chromophobe component producing beta-human chorionic gonadotropin. Int J Urol 2005, I 2:835-837.

8. Chua SL, Rosenthal MA, Wong SS, Ashley DM, Woods AM, Dowling A, Cher LM: Phase 2 study of temozolomide and Caelyx in patients with recurrent glioblastoma multiforme. Neuro-oncol 2004, 6:38-43.

9. Bogdahn U, Jauch T, Beier C, Beier D, Ganssbauer S, Glas M, Koch H, Wismeth C, Steinbrecher A, Hau P: Combined regimen of temozolomide and liposomal pegylated doxorubicin in glioblastoma - Toxicity and efficacy. J Clin Oncol (Meeting Abstracts) 2006, 24: II50I.

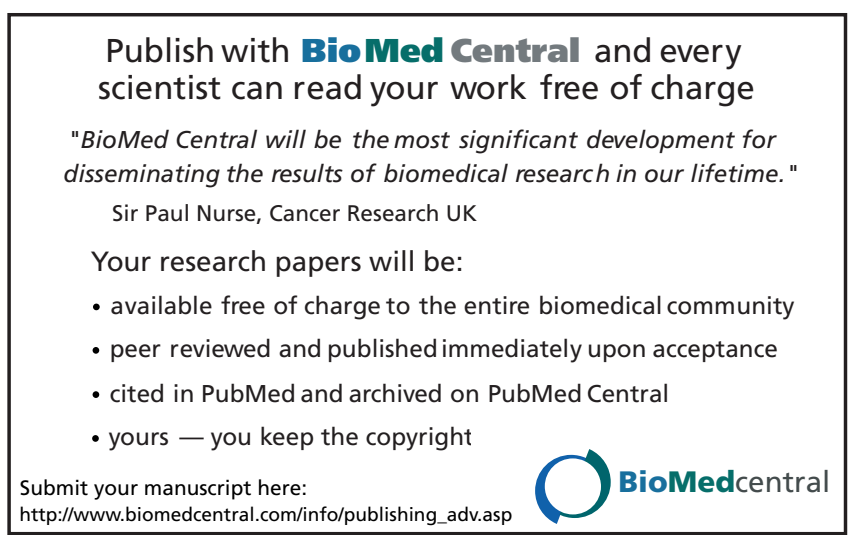

